\title{
Internet Addiction and Psychosocial Functioning among University Students
}

\author{
Hafsa Ahmed \\ The UCL Academy, London, UK.
}

\begin{abstract}
In the past decade, research has accumulated signifying that excessive Internet use can lead to the development of behavioral addiction. Internet addiction has been measured as a danger to mental health and excessive internet usage has been connected to a variety of harmful psychosocial consequences. The research aims to investigate internet addiction and psychosocial functioning among university students. The study was descriptive. The research objectives included exploring the relationship between Internet Addiction and psychosocial functioning among university students, finding out the statistical difference between psychosocial functioning and duration of daily internet use, and studying the demographical variation such as age, gender, etc among university students influencing Internet Addiction and psychosocial functioning. To achieve these objectives, stratified random sampling was used to collect data from male and female university students of 2 public and 2 private universities in Islamabad. The results show an association between internet addiction and psychosocial function among university students. It further elaborates that male university students are more internet-addicted than females whereas females show higher psychosocial functioning. The result also illustrates that young university students are more internet addiction and psychosocial functioning than other ages. It further explains that a private university shows more internet addiction and psychosocial functioning than a public university.
\end{abstract}

Keyword: Internet Addiction, Psychosocial Functioning, university

\section{Introduction}

Internet is a scientific instrument that has a social, cultural, political, and economic magnitude in the information society. Computer usage has the prospective to build up and modify the accessible societal arrangement of culture. Internet has become a fundamental component of everyday life as it is all over the world. Internet is a bridging instrument that crafts our life easier and has become an indispensable commodity of connecting the thousands of user population around the globe.

The Internet provides practical functions like entertainment, shopping, social sharing applications that facilitate accessing information easily and quicker (Young, 1998) simultaneously with physical and emotional problems like fatigue aggression, sadness, isolation (Morahan-Martin and Schumacher, 2003). Additionally, educational problems like bad academic performance wasting time (Griffiths, 2000), Friends communication difficulties (Morahan-Martin and Schumacher, 2000).

Though the internet plays an oblique role in these problems, internet addiction influences these issues directly (Young, 1998). Addiction has comprehensively explained as a psychiatric 
condition to recognize challenging internet use connected with major psychological, social, and professional impairment. Indications of extreme internet usage, amplified nervousness when off-line, hiding or deceitful about the degree of online use, destruction to real-life performance and also directly escort to social loneliness, augmented depression, ancestral discord, academic disappointment, economic debt, and job dissatisfaction (Young 1998).

Addiction is coined as individuals feeling of need for something (like another person, substance, etc.) to maintain her/his survival and carry on her/his way of survival as she/he wishes (West, 2005). DSM IV codes enclose the saying "very strong need or compulsion towards taking a substance" for addiction (APA, 1994). The word internet addiction was first conceptualized by Goldberg (1996) and by following DSM IV addiction criterion it was coined as "very strong wish or urge for using the internet" (Block, 2008; Korkeila et al. I 2009).

There are obvious differences between standard internet practice and addicted / passionate internet usage (Aboujaoude, 2010). People use the internet for daily use for necessities within motivation, they can organize themselves while using it, and they demonstrate usual behaviors when they inaccessibility to the internet (Young, 1998).

Internet Addiction is a subtype of an addiction disorder, which is portrayed by excessive or uncontrolled internet usage with pessimistic outcomes for psychological, social, and work performance (Young, 1998). It involves Tolerance, Salience, Mood-modification, Relapse, withdrawal, and conflicts as measured by a rating scale. A high score on the scale will indicate a high level of internet addiction.

Along with internet addiction, psychosocial functioning is studied as our psychological, emotional, and social well-being. It influences how we imagine, experience, and proceed with life. It concludes how we handle anxiety, depression, and make preferences (WHO,2007). It is supported on Emotional symptoms, Prosocial, Conduct troubles, Hyperactivity-inattention \& friend troubles as calculated by a rating scale.

The necessity to spend an escalating sum of time on computer actions such as playing internet games, organizing data files, or involved in online discussion groups is signified by psychological acceptance. Internet users are conscious of this problematic conduct but they continue to use the computer instinctively. Additionally, difficulty or pathological internet users are in intense emotional action (thinking continually about the internet) (Young, 1998). It is considered that necessitate for amplified internet usage to get the happiness they desire, fail in their attempt to classify, reduce their internet usage leading to anxiety, fatigue, and aggression.

Various researches about the causes of internet addiction illustrate that characteristics like nervousness, depressive symbols, and little self-esteem are accredited with leaning towards internet addiction (Yang Tung, 2007). Moreover, social sharing sites like Facebook, Twitter, online games and online gambling causes an increase in the number of internet addiction cases and it is stated that internet addiction will become a serious problem in the near future (Teke, 2011).

Internet Addicts are more destructive and lonelier than non-internet addicts, the significant differences were found between addicts and non-addicts. Pathological internet game addiction forecasts loneliness and destructive performance (Qureshi, Khan, \& Masroor, 2013). Males are more challenging gamers than females. 190 participants were recognized as problematic internet users while 165 were identified as non-problematic internet users. It means that online internet usage in Pakistan is addicted to online games as in another part of the world (Khan \& Muqtadir, 2012). 
Internet addiction, a new category of addiction, became an imperative topic in different disciplines including psychology, sociology, and communication. University Students are more close to expertise so their relationship with computers and the internet has significance for researchers from several fields. Therefore in the field of education to obtain full advantage from computers; research is comprehensive at each level in many areas so the present research aims to study the Internet addiction and psychosocial functioning among university students.

\section{Objectives of the study}

1. To explore the relationship between Internet Addiction and psychosocial functioning among university students.

2. To find out the statistical difference between psychosocial functioning and duration of daily internet use.

3. To study the demographical variation such as age, gender, etc among university students influencing Internet Addiction and psychosocial functioning.

\section{Hypotheses}

1. Is there a relationship between Internet Addiction and psychosocial functioning among university students?

2. Is there a statistical difference between psychosocial functioning and the duration of daily internet use?

3. What is the role of demographical variation such as age, gender, etc among university students influencing Internet Addiction and psychosocial functioning?

\section{Research design}

The research study was descriptive in nature. Survey Method was used for the collection of data and descriptive analysis was used to analyze the study.

\section{Sample}

The sample of the study consists of male $(n=50)$ and female $(n=50)$ university students of Islamabad. A stratified random sample was used to collect data from 2 public and 2 private universities of Islamabad.

\section{Research Instrument}

The research study was cross-sectional in nature so the questionnaire was an ideal research instrument to collect data from university students. Psychological Functioning was developed by Ryff (1989) in order to evaluate individuals' psychological. There are six factors, each of which is composed of 14 items, in the scale of psychological well-being, which was developed to measure autonomy, environmental dominance, personal development, positive relations with others, purposes of life, and self-acceptance.

Online Cognition Scale (OCS) was used in order to measure internet addiction (Davis et al., 2002; Ozcan and Buzlu, 2005). The referred scale includes 36 items on a 7 -point Likert-type scale $(1=$ strongly disagree to $7=$ strongly agree). Sub-dimensions are composed of, Diminished impulse control (10 items, e.g., I use the Internet more than I ought to), loneliness/depression (6 items, e.g., I am bothered by my inability to stop using the Internet so much), social comfort (13 items, e.g., When I am online, I can be carefree), and distraction (7 items, e.g., I often use the Internet to avoid doing unpleasant things).

\section{Data Analysis}

Data collected from the questionnaire was analyzed with the help of SPSS 16 software. In order to determine the effect of demographic variation among university students and seek out psychometric properties for research instruments different statistical techniques were applied like mean, Standard deviation, Conbrach Alpha Reliability, and ANOVA. 


\section{RESULTS}

The research aimed to explore the relationship between Internet addiction and psychosocial functioning among university students. The research was carried on a sample of 50 males and 50 female university students of public and private universities in Islamabad. The reliability of IA and PF was calculated through Conbrach Alpha Reliability. The reliability of the IA questionnaire 0.8534 and the reliability of the $\mathrm{PF}$ questionnaire was 0.817 . It exposes that instrument has highly reliable to measure the relationship between Internet addiction and psychosocial functioning among university students.

\section{Inter scale correlation of student scores on Internet Addiction}

Table 1

\begin{tabular}{lllll}
\hline IA & $\mathbf{1}$ & $\mathbf{2}$ & $\mathbf{3}$ & $\mathbf{4}$ \\
\hline Diminished impulse control & 1 & & & \\
Distraction & $.60^{* *}$ & 1 & & \\
Loneliness / Depression & $.78^{* *}$ & $.54^{* *}$ & 1 & 1 \\
Social Comfort & $.76^{* *}$ & $.42^{* *}$ & $.80^{* *}$ & 1 \\
\hline
\end{tabular}

Table 1 shows the Inter scale correlation of student scores on Internet Addiction. It clearly portrays a significant correlation between subscales of Internet Addiction. There is a significant positive correlation between Loneliness and Social Comfort $\left(\mathrm{r}=.80^{* *}\right)$.

Inter scale correlation of student scores on Psychosocial Functioning

Table 2

\begin{tabular}{lllllll}
\hline & 1 & 2 & 3 & 4 & 5 & 6 \\
\hline Autonomy & 1 & & & & & \\
Environmental dominance & .275 & 1 & & & & \\
Personal development & .165 & .171 & 1 & & & \\
Positive relations with others & $.233^{*}$ & .181 & $.457^{*}$ & 1 & & \\
Purposes of life & .189 & .228 & .346 & $.545^{*}$ & 1 & \\
Self-acceptance & .276 & .243 & $.352^{*}$ & $.464^{*}$ & .339 & 1 \\
\hline
\end{tabular}

Table 2 shows the Inter scale correlation of university student scores on Psychosocial Functioning. It clearly portrays that there is a positive association among subscales of Psychosocial Functioning. There is a positive association between the purpose of life and Positive relations with others $\left(\mathrm{r}=.545^{*}\right)$. There is an association between Positive relations with others and personal development $\left(\mathrm{r}=.457^{*}\right)$.

Correlation between Internet Addiction and Psychosocial Functioning

Table 3

IA

IA PF

$\mathrm{PF} \quad 0.76^{* *}$

Table no 3 shows there is a positive association correlation between Internet Addiction and Psychosocial Functioning among university students.

Age-wise Comparison of Mean of Internet Addiction and psychosocial functioning among university students 
Table 4

\begin{tabular}{|c|c|c|c|}
\hline Age & $18-22$ & $23-27$ & $28-32$ \\
\hline IA & 14 & 12 & 10 \\
\hline PF & 11 & 13 & 9 \\
\hline
\end{tabular}

Table no 4 shows age-wise mean scores among university students regarding internet addiction and psychosocial functioning. It clearly illustrates that Internet addiction is higher among 1822 years of university students as compared to other age groups whereas Psychological Functioning is higher among the age group 23-27 years as compared to others.

\section{Gender wise Comparison of Mean of Internet Addiction and psychosocial functioning} among university students

Table 5

\begin{tabular}{|c|c|c|}
\hline Gender & Male & Female \\
\hline IA & 15 & 14 \\
\hline PF & 10 & 12 \\
\hline
\end{tabular}

Table no 5 shows gender-wise mean scores among university students regarding internet addiction and psychosocial functioning. It clearly illustrates that Internet addiction is higher among male university students as compared to female whereas Psychological Functioning shows a frequently higher mean among females as compared to male.

\section{Qualification wise Comparison of Mean of Internet Addiction and psychosocial} functioning among university students

Table 6
\begin{tabular}{|c|c|c|c|}
\hline Qualification & BS & MS & PhD \\
\hline IA & 15 & 14 & 13 \\
\hline PF & 14 & 12 & 13 \\
\hline
\end{tabular}

Table no 6 shows qualification wise mean scores among university students regarding internet addiction and psychosocial functioning. It clearly explains that Internet addiction is higher among BS university students as compared to other levels whereas Psychological Functioning is also higher among BS university students too.

\section{Sector-wise Comparison of Mean of Internet Addiction and psychosocial functioning among university students}

Table 7

\begin{tabular}{|c|c|c|}
\hline Sector & Private & Public \\
\hline IA & 16 & 14 \\
\hline PF & 15 & 13 \\
\hline
\end{tabular}

Table 7 shows sector-wise mean scores among university students regarding internet addiction and psychosocial functioning. It clearly portrays that Internet addiction is higher among private university students as compared to the public whereas Psychological Functioning is higher among public university students compared to public.

One way ANOVA

Table 8

\begin{tabular}{|lccc|}
\hline $\begin{array}{l}\text { ANOVA } \\
\text { SIG }\end{array}$ & DF & Mean Squares & F \\
\hline Between Groups & 5 & 2345.67 & 278.1 \\
\hline
\end{tabular}




\begin{tabular}{|lll|}
\hline 0.00 & & \\
\hline Within Groups & 94 & 8.94 \\
\hline
\end{tabular}

Table no 4 shows one way ANOVA of Internet Addiction and Psychosocial Functioning among university students. It clearly illustrates that $5 \%$ level of significance, F-value is statistically significant which shows a relationship between Internet Addiction and psychosocial functioning among university students.

\section{Conclusion and Discussion:}

In general Internet, Addiction is an emergent problem and quite prevalent in our locality. The problem is higher among university students. However, there are a lot of factors that contribute to internet addiction. Online internet surfing is one major factor in a high level of internet addiction with the local availability of networks. The study aims to investigate internet addiction and psychosocial functioning among university students. The study is descriptive. The research objectives are as follows: To explore the relationship between Internet Addiction and psychosocial functioning among university students, To find out the statistical difference between psychosocial functioning and duration of daily internet use, and to study the demographical variation such as age, gender, etc among university students influencing Internet Addiction and psychosocial functioning. The results portray an association between internet addiction and Psychosocial functioning as an increase in the use of the internet leads to anxiety, depression and negative attitude, etc (Akın, 2012; Caplan, 2003; Ferraro, Caci, D'Amico, et al. 2007). The study concludes that internet addiction is higher among young University students as they have to complete projects, assignments, and other content. It also appears that male university students are more internet addicts than female university students due to online content and activities. Likewise, private university students show higher risk possibility due to their ease of access (connected WIFI on campus), their social status, and more internet availability. The degree of psychosocial functioning may vary in different dimensions. However, Internet addiction is connected with higher levels of loneliness, poorer social adaptation, and emotional ability (Engelberg, and Sjoberg, 2004) and those with the most ruthless shared interaction feel nervousness spent the most time online (Erwin et al., 2004; Wolfradt, and Doll, 2001). Therefore, it emerges that if persons can improve their psychological functioning, they may decrease their internet addiction.

In conclusion, this research argued that Internet addiction may have an everlasting effect on psychological functioning. University Students high in Internet addiction are more likely to be low in psychosocial functioning. Therefore, the present findings enhance our understanding of the relationship between psychosocial functioning and Internet addiction. In addition, enhancing psychosocial functioning levels of university students may also have a precautionary function for Internet addiction.

\section{Recommendation}

Attention to the degree of this issue ought to be sought after by teachers, educators, open authorities, yet most particularly university understudies. This can be accomplished through the appropriate and right finding of web fixation. Emotional well-being experts and paraprofessionals (clinicians, counselors" ${ }^{\prime \prime}$, and social specialists) ought to effectively evaluate if the web is the reason for the fundamental issue or the web is a way of dealing with stress for the basic issue. University instructors and/or University clinicians might likewise use their guiding focuses/University facilities as screening centers for understudies associated with being dependent on the web and web applications.

For University, with restricted access to direction instructors or other emotional wellness experts in the school settings, it is prescribed that even educators know about the notice indications of juvenile web habit. By utilizing accessible assets, for example, educators and 
school medical caretakers, projects may be planned in the school upholding counteractive action and sound utilization of the web. The direction focus may spread data administrations, for example, flyers, pamphlets, postcards, and posting blurbs in the school release loads up on the negative impacts of web abuse. They should likewise give data on accessible administrations in the school, for example, directing, and care groups accessible to understudies with distinguished issues identified with web use. Maybe, adding data administrations to the "understudy manual" rather than simply putting tenets and regulations. As there is no space for medicinal direction and preventive activities in the "understudy guidebook" university heads may incorporate accessible health programs, extracurricular exercises, and volunteer works expressing the targets of such projects and how it can advantage the prosperity of the understudies. Such projects ought to catch the understudy's advantage and reasonable and viable in giving psychological well-being and life aptitudes improvement for the young.

For the legislature and different organizations, subsidizing in the improvement extends that or existing projects that are intended to build social abilities (e.g. bunch motion), foster selfimprovement and self-acknowledgment (e.g. mindfulness), expand self-governance and autonomy (e.g. self-assuredness preparing), build reason in life and ability to know east from the west (e.g. memories), expand their ecological authority (e.g. ability and aptitudes improvement class), build profound knowledge (e.g. intelligent exercises/otherworldly direction exercises), diminish social attractive quality ( self coordinated exercises) and expanding gainful change and adapting (e.g. anxiety questioning and wellbeing projects) must be executed and customized into psychological wellness programs accessible in our locality.

\section{References}

[1]. Aboujaoude, E. (2010). Problematic Internet use: an overview. World Psychiatry, 9(2), 85-90.

[2]. Block, J.J. 2008 Issues for DSM-V: Internet addiction [Editorial] The American Journal of Psychiatry, 165, pp. 306-307.

[3]. Griffiths, M. D. (2000). Does the Internet and computer "addiction" exist? Some case study evidence. CyberPsychology and Behavior, 3 (2), pp. 211-218.

[4]. Korkeila, J., Kaarlas, S., Jaaskelainen, M., Vahlberg, T., and Taiminen, T. (2010) Attached to the web-harmful use of the Internet and its correlates. Eur. Psychiatry 25(4), 236-241.

[5]. Morahan-Martin, J., and Schumacher, P. (2000). Incidence and correlates of pathological Internet use among college students. Computers in Human Behavior, 16, 13-29.

[6]. Teke, R. (2011).A Comparison of Facebook Addiction between Social and Hard Sciences Students. Unpublished MA thesis, Faculty of Communication, and Media Studies. Eastern Mediterranean University.

[7]. West, R. (2005) Time for a change: putting the Transtheoretical (Stages of Change) Model to rest. Addiction, 100, 1036-1039.

[8]. Yang, S., and Tung, C. (2007). Comparison of Internet addicts and non-addicts in Taiwanese high school. Computers in Human Behavior, 23(1), 79-96.

[9]. Young K. S. and Rogers R. C. (1998). The relationship between depression and Internet addiction. Cyber Psychology and Behavior, 1, 25-28.

[10]. Young, K.S. (1998) Caught in the Net: How to Recognize Internet addiction and A Winning Strategy for Recovery. New York, NY: John Wiley and Sons, Inc. 